\title{
Experimental investigation of water composition and salinity effect on the oil recovery in carbonate reservoirs
}

\author{
Seyyed Hayan Zaheri, Hossein Khalili*, and Mohammad Sharifi \\ Department of Petroleum Engineering, Amirkabir University of Technology, 159163-4311 Tehran, Iran
}

Received: 4 June 2019 / Accepted: 3 February 2020

\begin{abstract}
Water injection has been known as a conventional approach employed for years in order to achieve higher oil recovery from oil reservoirs. Since the last decade many researchers conducted on the water injection assessment suggested that low salinity water flooding can be an effective flooding mechanism and it can be used as an enhanced oil recovery method. Several examinations were conducted to identify governing mechanisms entailed in oil extraction and the effect of salinity and different types of ionic contents contained in Formation Water (FW) and injected fluid. This study is dedicated to address the influence of salinity and different types of ionic contents contained in formation water and injected fluid on incremental oil recovery. For this purpose, fluid-fluid and rock-fluid interaction were investigated especially for evaluating the effect of calcium ions in the formation water and sulfate ions in the injected water. Several experiments were carried out including core-flooding, contact angle, and imbibition tests. While former researchers concluded that reducing the salinity of injected water causing a decrease in ionic strength may lead to a greater oil recovery, in this research, we showed that these statements are not necessarily true. It was observed that existence of the high calcium concentration in the formation water would cause significant effect on wettability status of rocks and final oil recovery during low salinity water injection. This process is mainly due to rock wettability alteration. Wettability alteration mechanism in carbonate rocks is explained through interaction between rock and fluid composition. The results indicate the decisive role of calcium ions in the formation water at all stages from aging in oil to primary and secondary recovery. In addition to that, it was observed that more sulfate ion concentration in the injected water enhances rock wettability alteration.
\end{abstract}

\section{Introduction}

Carbonate reservoirs hold about $60 \%$ of oil and $40 \%$ of global gas resources [1]. These types of reservoirs are also prone to contain high permeability fracture networks alongside the matrix with low permeability. Carbonate rocks show oil-wet tendency in many cases which can be a critical parameter for oil recovery during the lifetime of the reservoir [2]. This can be very critical especially in case of water injection which is accepted as one of the convenient secondary recovery approaches [3]. In case of oil-wet systems and especially in fractured reservoirs, spontaneous water imbibition will be minimized and capillary forces act against oil extraction from the low matrix blocks.

In the first steps of flooding, the amount of injected water was thought to be important factor but gradually some researchers debated that the water quality is the most important parameter. Since then, many researches were conducted to address an operational and economical solution to overwhelm constraints.

\footnotetext{
* Corresponding author: ho3inkhalili@aut.ac.ir
}

Low salinity flood execution was firstly introduced at 90's, while experiments were established on examination of salt water, crude oil, petrology, and empirical methods for wettability alteration in EOR processes [4]. Morrow et al. made observations during working on the wettability effect on production efficiency and stated that the change in injected water composition can improve recovery [5]. Tang and Morrow expressed the similar oil extraction results due to water injection with high salinity and low salinity when water saturation is zero. This claim was approved and revised by Zhang and Morrow and proposed as the necessity of having primary water saturation for the effectiveness of low salinity water oil recovery to enhance it $[6,7]$. Afterward, Zhang et al. endorsed the effectiveness of water composition but pointed out that this increase happens under particular circumstances of the crude oil/saltwater/rock interactions [8]. Earlier studies have shown that water with low salinity can be used in both carbonate and sandstone reservoirs at appropriate times. Several mechanisms have been proposed in the literature for the performance of low salinity water injection in the sandstone reservoirs. Tang and Morrow have suggested that increased oil recovery by 
this way was due to the expansion of the double layer during the salinity reduction, and consequently, easier dispersion of clay with bonded oil components. When the salinity decreases, thereby double layer will expand and polar components of the oil have been bonded to the divalent cations can be exchanged [9]. In sandstone reservoirs due to the presence of clay and the exchange of ions with the formation water, the increase in oil recovery is attributed to the diluted saline water injection, because clay in conjunction with low salinity water swells and these reactions lead to displacement of the oil entrapped within clay. In the case of high salinity water injection, these particles are not separated from the rock surface and thus oil-wet system is preserved. In carbonate reservoirs, clay is usually low and if present, it is trapped in the rock matrix and its surface contact with the reservoir's fluids is negligible; therefore, water injection with low salts in these reservoirs is not usually effective. In these reservoirs, smart water can be attributed to the measured selection of ionic concentrations, and most of the water with moderate salinity, such as seawater, is nominated as candidates for injections into these reservoirs [10].

Mechanisms in charge of this phenomena are ambiguous and involve some uncertainties. Some inconceivable observations were found out from published reproduction results of generalized laboratory expectations in comparison to field scale. The effect of low salinity water injection on carbonate formation has not been thoroughly explained in contrast to sandstone rocks. The defective term presenting this deputation is thought to be wettability alteration by low salinity water with respect to clay components participation, which is not the case in carbonate rocks $[5,8$, 11-15]. Wettability alteration is the main challenge for enhanced oil recovery from carbonate reservoirs. The occurrence of any change in the wettability, the activation energy for chemical reactions is essential. Overall, the bond energy between polar components of oil and carbonate is higher than that seen in the sandstones. Carbonate rocks wettability is mixed to oil-wet, due to the adsorption of carboxylic components in crude oil on the surface [16].

Many researchers tried to analyze water salinity effect on recovery cooperating with the British Petroleum Company $(B P)$ [11-13]. It was a step forward to make a way for testing their work in an affordable range of field pilot flooding in both secondary and tertiary forms, single-well tracer test and log inject log. Later, such activities led to EOR-LoSal trademark popularity that make it to be attended by big companies like Total, Shell, Statoil, and lot of universities [17].

In 1998, Sharma and Filoco introduced water salinity as an important parameter in final oil recovery. In their test, the amounts of formation water salinity were $0.3 \%, 3 \%$, $20 \% \mathrm{NaCl}$, and $3 \%$ injection water salinity, which caused a significant increase in oil recovery for salinized water. The significant increase in oil recovery showed the effectiveness of the salinity. In this study, it was investigated to change water-wetting settlements into a mixed-wet zone within the drainage process. They concluded that the remaining oil content in plug-ins in the case of presumed mixed wetting was less than that of water-wet or oil-wet
[18]. After reducing water salinity the better result in recovery was achieved and confirmed later in the paper released by Zhang and Morrow [7] and McGuire et al. [19].

The effects of low salinity water are generally observed that once an increase is noticed in oil recovery, the salinity of injected water is less than available/formation water. Anyway, there is still a chance for these results not to match the real data outputs obtained from pilot tests. As salinity goes up, the number of electrostatic repulsion increases due to the surface loads abandonment $[20,21]$ and the saltwater film becomes more unstable as a result. Although this was not demonstrated in Sharma and Filoco experiments in contrast with most published articles, reduction of injectable water salinity compared to formation water will improve recovery. In 2005, McGuire et al. rendered a Single-Well Chemical Tracer Test (SWCTT) and no progress obtained in recovery results with injected water at salinity values greater than $7000 \mathrm{ppm}$ [19]. Nasralla et al. used spontaneous imbibition concept and qualitative USS experiments in flooding performance evaluation. In this study, maximum oil recovery by low salinity flooding occurred for brine injection case at a certain salinity threshold, in which it is not expected to reach any additional recovery below that limit [22]. Based on a representative number of observations from many authors it can be acclaimed that a relative optimal salinity which is not too much concentrated nor too diluted, will cause better extraction results under imbibition conditions in presence of sulfates [23, 24]. RezaeiDoust et al. found out that calcium, magnesium, and sulfate ions concentration to be the key parameters which are taking roles in wettability alteration during a saltwater/brine injection EOR [16].

In 1995, Jadhunandan and Morrow assessed wettability dependence on water initial saturation. The higher the saturation of primary water is the plug estimates to have more water-wetness likelihood [3]. These results were consistent with Sharma and Filoco experiments in 1998. Their experiments showed that plugs with a low concentration of calcium ions in formation water (or ionic strength) trends a more dramatic peak on the profile. Therefore, the effectiveness of low salinity water is probably related to the wettability since in high-salinity formation water plugs, injecting water with low salinity can make them water-wet and develop production [21].

In the following, the surfactant influence in reducing interfacial tension and changing wettability in carbonate rocks was mentioned as the other aspect of considerations in order to achieve more sweep efficiency. Standnes and Austad used chemical additives in four-linked ammonium cationic surfactant $(\mathrm{R}-\mathrm{N}(\mathrm{CH} 3) 3 \mathrm{Br}$ ) combined in the injected water to be used in changing the wettability of carbonate rocks [25]. In surveys conducted by Austad et al., the presence of sulfate ions as catalysts showed to make a difference in wettability regarding cationic surfactants [26]. Subsequently, Zhang and Austad [27] suggested the sulfate ion as the only adequate consideration to improve change of wettability in carbonate formations denying the use of surface-active agents especially avoiding high expense of application [28-30]. Published experimental data suggests that desorption of acidic oil components from rock 
surfaces make carbonate rocks more water-wet. One widely accepted mechanism is that sulfate $\left(\mathrm{SO}_{4}^{2-}\right)$ replaces the adsorbed carboxylic group from the rock surface while cations $\left(\mathrm{Ca}^{2+}, \mathrm{Mg}^{2+}\right)$ decrease the oil surface potential [31].

The common idea of the whole previous analyzes indicated the effectiveness of $\mathrm{Ca}^{2+}, \mathrm{Mg}^{2+}$, and $\mathrm{SO}_{4}^{2-}$ in seawater/brine injection process. Brines are naturally rich in $\mathrm{Ca}^{2+}, \mathrm{Mg}^{2+}$, and $\mathrm{SO}_{4}^{2-}$ portions which initiate the extraction improvement. Beside these statements, there is still a problem about mitigating unwilling particle's concentration. It can be managed through selective reduction or elimination of $\mathrm{Ca}^{2+}$ or $\mathrm{Mg}^{2+}$ low salinity flooding that discussed by Gupta et al. [32] and Ligthelm et al. [33]. In this procedure, some indices are required to imply the selective choice. Seyyedi et al. discovered that magnifying $\mathrm{SO}_{4}^{2-}$ portion of SW by four, did not represent further development in final extraction which also applies to increase of $\mathrm{Ca}^{2+}$ content and $\mathrm{Ca}^{2+} / \mathrm{Mg}^{2+}$ ratio at a constant temperature of $60{ }^{\circ} \mathrm{C}$ [34]. Zhang et al. investigated the potential of using seawater or modified seawater as an IOR fluid in moderate waterwet to preferential oil-wet range of reservoirs and fractured chalk oil formation. They concluded that seawater, which contains the possible potential of ions $\left(\mathrm{Ca}^{2+}\right.$ and $\left.\mathrm{SO}_{4}^{2-}\right)$, can increase the water-wetting nature of chalk, and thereby the capillary forced dominancy in water imbibition process into the oil contenting matrix blocks $[8,28,35]$ where Strand et al. also confirmed this fact [36]. Yousef et al. investigated the impact of salinity and ionic composition on oil/brine/rock interactions and eventually on the oil recovery. They studied on wettability, surface chemistry, Nuclear Magnetic Resonance (NMR), and zeta potential to define the role of water ions in the induced wettability alteration. Their results showed that altering the salinity and ionic composition of the injected water has a significant impact on the wettability of the rock surface [37-39]. In addition, their results confirmed that injecting diluted seawater is able to change surface charge of carbonate rock toward more negative, lead to more interactions with water molecules, and eventually alter rock wettability [40]. Al-Shalabi et al. investigated the mechanism behind the low salinity water injection effect on oil recovery through history matching of oil recovery and pressure drop data for first and second core-flooding experiments of Yousef et al. [37] work. They used the UTCHEM simulator, which is a 3D multiphase flow simulator. They found that wettability alteration is still believed to be the reason for the low salinity water injection effect on oil recovery [41-43]. Kazemi Nia et al. applied their integrated simulator to model the entire produced ion histories of a core-flood data published by Kozaki [44] and the field trial performed by BP America Incorporated at the Endicott field [45-48]. Purswani and Karpyn conducted a series of waterflood experiments at $90{ }^{\circ} \mathrm{C}$ with synthetic seawater type brine solutions with varying compositions of potential determining $\left(\mathrm{Ca}^{2+}\right.$, $\mathrm{Mg}^{2+}$, and $\mathrm{SO}_{4}^{2-}$ ) [49].

This study aims to shed lights on possible mechanisms behind low salinity water injection and possible effect of the formation water composition on the flooding process. This was achieved using several experiments (including contact angle, imbibition, and core-flooding) and then try to justify observations using appropriate mechanisms.

\section{Materials}

\subsection{Porous medium}

In this study, several core plugs of a carbonate oil reservoir from Asmari outcrops near the southern part of Iran were used as a porous medium to conduct core-flooding and imbibition experiments. These plugs were roughly similar in terms of porosity and permeability with around $20 \%$ and $45-60 \mathrm{mD}$ respectively. For measuring the contact angle, several thin sections from each rock were prepared. After all, the obtained core properties were listed in Table 1. Plugs \#1-3 were picked for flooding tests and plugs 34,31 , and 36 were used for imbibition test.

\subsection{Formation water}

Here, three kinds of formation brine with total density of almost identical particles, meaning the same number of dissolved ions, were prepared. Different concentrations of calcium ions in formation brine (0-Ca, Main-Ca, 3-Ca) have been used to provide a more clear understanding of mechanisms governing the enhanced oil recovery. The compounds of Main-Ca are in accordance with the base Formation Water (FW), 3-Ca represents the formation water with three times of the calcium concentration in the base case (Main-Ca) and 0-Ca represents the formation water with no concentration of calcium. The ion composition of the $\mathrm{FW}$ is given in Table 2.

\subsection{Injection water}

Two types of injected water are involved with similar amounts of particles but have different concentrations of sulfate ion (PG, PG3\#S). The ions and PG injection compounds correspond in Persian Gulf Sea water, and PG3\#S reflects the injected water with three times the concentration of sulfate in compare with base case (PG). The composition of injected water is given in Table 3 .

\subsection{Oil}

All the assessments are conducted on an oil sample from a reservoir in the western south of Iran with crude oil density of $0.844 \mathrm{~g} / \mathrm{cm}^{3}$, API of 29.8 and a viscosity of $8.93 \mathrm{cp}$ at $25^{\circ} \mathrm{C}$ presented in Table 4 . In fluid-fluid interaction study, categories of filtered crude oil samples were used and filtration practice was performed to remove any external particles that might be added to the oil sample during the production period.

\section{Experimental procedure}

\subsection{Core preparation}

In the first step, core plugs are cleaned by toluene/methanol through soxhlet extraction apparatus and heated in the 
Table 1. Basic petrophysical properties of carbonate core plugs.

\begin{tabular}{lcccc}
\hline Keyphi information* & Porosity $(\%)$ & $K_{\text {air }}(\mathrm{mD})$ & Grain density $\left(\mathrm{g} / \mathrm{cm}^{3}\right)$ & Pore volume $\left(\mathrm{cm}^{3}\right)$ \\
\hline Plug 1 & 20.37 & 54 & 2.85 & 17.6 \\
Plug 2 & 21.6 & 61 & 2.85 & 18.5 \\
Plug 3 & 21.5 & 60 & 2.85 & 15.02 \\
Plug 34 & 19.11 & 52 & 2.85 & 16.22 \\
Plug 36 & 21.1 & 45 & 2.85 & 18.32 \\
Plug 31 & 19.9 & 50 & 2.85 & 17.6 \\
\hline
\end{tabular}

* The KEYPHI is a fully automated multi-sample permeameter and porosimeter dedicated to measuring the porosity and permeability to helium/nitrogen of plug-sized core samples.

Table 2. Geochemical analysis of the formation brines.

\begin{tabular}{lccc}
\hline Ion & $\begin{array}{c}(0-\mathrm{Ca}) \\
\mathrm{mg} / \mathrm{L}\end{array}$ & $\begin{array}{c}(\text { Main-Ca }) \\
\mathrm{mg} / \mathrm{L}\end{array}$ & $\begin{array}{c}\text { (3-Ca) } \\
\mathrm{mg} / \mathrm{L}\end{array}$ \\
\hline $\mathrm{Na}^{+}$ & 84798 & 75198 & 55998 \\
$\mathrm{Ca}^{2+}$ & 0 & 9600 & 28800 \\
$\mathrm{Mg}^{2+}$ & 1458 & 1458 & 1458 \\
$\mathrm{SO}_{4}^{2-}$ & 550 & 550 & 550 \\
$\mathrm{HCO}_{3}^{-}$ & 448 & 448 & 448 \\
$\mathrm{Cl}^{-}$ & 136675 & 136675 & 136675 \\
$\mathrm{TDS}$ & 223929 & 223929 & 223929 \\
Ion strength & 3.908 & 4.177 & 4.718 \\
Molar conc.(mol/L) & 7.618 & 7.44 & 7.083 \\
\hline
\end{tabular}

Table 3. Geochemical analysis of the injected brines.

\begin{tabular}{lcc}
\hline Ion & $P G(\mathrm{mg} / \mathrm{L})$ & PG3\#S $(\mathrm{mg} / \mathrm{L})$ \\
\hline $\mathrm{Na}^{+}$ & 12317.28 & 12317.28 \\
$\mathrm{Ca}^{2+}$ & 480.936 & 480.936 \\
$\mathrm{Mg}^{2+}$ & 1774.265 & 1774.265 \\
$\mathrm{SO}_{4}^{2-}$ & 3169.967 & 9509.88 \\
$\mathrm{HCO}_{3}^{-}$ & 122.0334 & 122.0334 \\
$\mathrm{Cl}^{-}$ & 23009 & 16669.08 \\
$\mathrm{TDS}$ & 40873.48 & 40873.47 \\
Ion strength & 0.829 & 0.87 \\
Molar conc. (mol/L) & 1.305 & 1.192 \\
\hline
\end{tabular}

oven at $80^{\circ} \mathrm{C}$ for two days. The dry weight, length, diameter, and porosity are then measured. To find porosity and permeability, Helium porosimeter, and liquid Hassler permeameter were used in the case. Next phase is to saturate plugs with the desired water in the desiccator.

\subsection{Water flooding}

FW-saturated plugs are exposed to the injected water. The absolute permeability can be measured from the pressure drop at the specified rate (to reduce the uncertainty, injections are conducted at three rates).

\subsection{Aging}

The aging process is consisted of putting the plug in the coreholder and inject the crude oil in a constant flow rate until the water saturation of the plug is reached to the irreducible water saturation $\left(S_{\mathrm{wi}}\right)$. Finally, when no more water was detected in test tubes at the outlet, having the input and output pressure one can calculate oil permeability at $S_{\mathrm{wi}}$. After oil flood operation, chemical equilibrium between the phases is established by aging plugs for three weeks at the temperature of $75{ }^{\circ} \mathrm{C}$ (Fig. 1).

\subsection{Preparation for core flooding experiments}

"The CFC-700, complete core-flood set" of the French Vinci Company is a tool that was used to inject fluids into cores. The setup has two syringe piston pumps being able to operate constant flows in a wide range of pressures. The dual pump allows to assign continuous pulses to flow at the desired temperature for the same pressure diversity. The fluid injection can be executed in two forms of constant pressure or constant flow rate. The setup can handle the flow rate from 0.01 to $25 \mathrm{~mL} / \mathrm{min}$ and the maximum pressure limit is $10000 \mathrm{psi}$.

\subsubsection{First injected water (PG)}

Seawater $(\mathrm{PG})$ was injected into the core in the order Five times of the Pore Volume (5PV) and when the oil at the outlet did not appear anymore, the primary water injection is stopped. Pressure changes recorded automatically and produced oil and water was recorded regularly using an automatic fraction collector. Eventually, it is possible to calculate relative permeability curves for the oil and water with available models (i.e., Purcell, Corey, Brooks-Corey model) using pressure data, fluid saturation, and recovery curves versus time. After injection of Two times of the Pore Volume (2PV) and not detecting any oil at the outlet, it is possible to calculate the effective water permeability at the remaining oil saturation $\left(K_{w}\right.$ at $\left.S_{\text {or }}\right)$. 
Table 4. Fluid properties of the oil sample.

\begin{tabular}{lccc}
\hline Specification & Unit & Qty & Test method \\
\hline Specific gravity at 15.056 & - & 0.8582 & ASTM D-4052 \\
Molecular weight & $\mathrm{g} / \mathrm{mol}$ & 194 & OSMOMETRIC \\
Sulphur content & $\mathrm{wt} \%$ & 1.17 & ASTM D-2622 \\
Salt content & $\mathrm{PTB}$ & 8 & ASTM D-3230 \\
Kinematic viscosity at $10^{\circ} \mathrm{F}$ & $\mathrm{cSt}$ & 21.005 & ASTM D-445 \\
Kinematic viscosity at $20^{\circ} \mathrm{F}$ & $\mathrm{cSt}$ & 12.896 & ASTM D-445 \\
Kinematic viscosity at $40^{\circ} \mathrm{F}$ & $\mathrm{cSt}$ & 6.592 & ASTM D-445 \\
Pour point & & $\leq 30$ & ASTM D-5853 \\
Reid Vapor Pressure $(\mathrm{RVP})$ & $\mathrm{psi}$ & 5.19 & ASTM D-323 \\
Wax content & $\mathrm{wt} \%$ & 12.2 & BP-237 \\
Acidity total & $\mathrm{mgKOH} / \mathrm{g}$ & 0.16 & UOP-565 \\
Nickel & $\mathrm{ppm}$ & 1.8 & ASTM D-5863 \\
Vanadium & $\mathrm{ppm}$ & $<3$ & ASTM D-5863 \\
Iron & $\mathrm{ppm}$ & $<1$ & ASTM D-5863 \\
Sodium & $\mathrm{ppm}$ & $<1$ & ASTM D-5863 \\
\hline
\end{tabular}
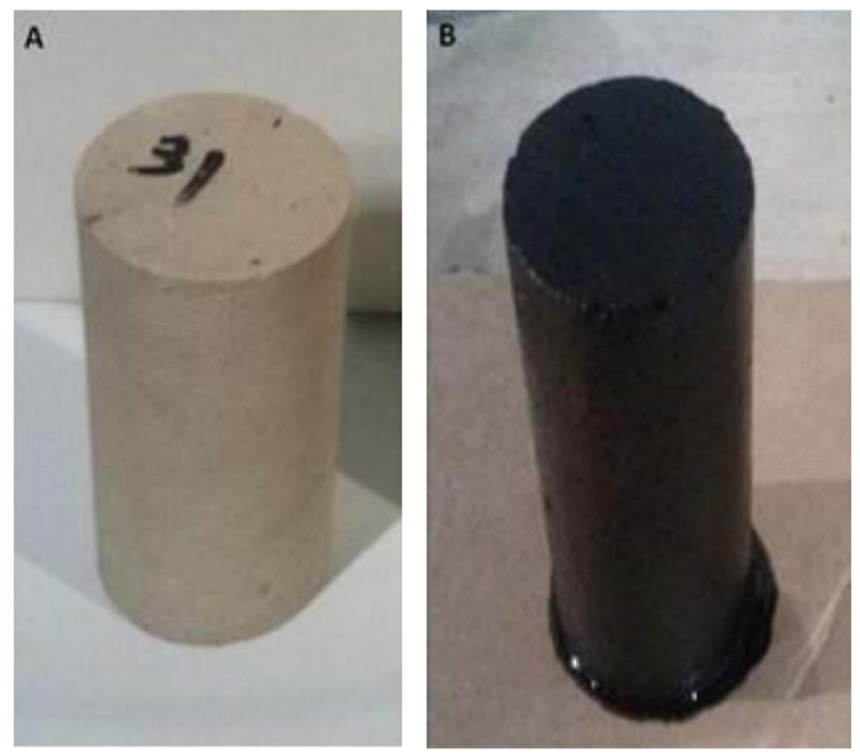

Fig. 1. Plug (a) before aging and (b) after aging.

\subsubsection{Second injected water (PG3\#S)}

Secondary injection water is conducted using 2-3 times of the pore volume (2PV-3PV). Here the composition of the injected water is different (PG3\#S). Injection was continued until no additional oil production was observed, and the pressure drop across the core was recorded for the permeability calculations.

\subsection{Preparation for spontaneous imbibition experiments}

Spontaneous imbibition experiments were conducted to check the initial wettability state of samples and the potential change of wettability by low salinity water. This test was conducted using a Pyrex Amott cells which can perform at high temperatures up to $200{ }^{\circ} \mathrm{C}$. Measurements of oil recovered by spontaneous imbibition was done in order to aid identification of wetting state of the cores.

Plugs \#31, \#34, \#36 which had similar characteristics in terms of permeability, porosity and pore volume, were selected for a couple of tests. Plugs first were saturated with specified formation water and then oil was injected using routine procedures performed for relative permeability assessment. After aging in crude oil for 3 weeks, spontaneous imbibition tests on three cores were performed for 24 days at three levels of temperature including 25, 50, and $80{ }^{\circ} \mathrm{C}$. After that, in order to evaluate the effect of the second injected water (smart water PG3 $\#$ S), the cores were placed in the vicinity of the second injected water for 8 days at $80^{\circ} \mathrm{C}$ (see Fig. 2).

\subsection{Preparation for contact angle experiments}

Contact angle tests are considered as one of the most common methods to quantify rock wettability. In this study, it was used to address the impact of different salinity on the carbonate rock wettability. Homogenous and polished slides were candidated to be analyzed in terms of contact angle before and after aging and to investigate the effect of injected water on the wettability state of rocks. The contact angle measurement executed before the aging process with various $\mathrm{FW}$ samples, and then after aging. Contact angles were mesured after aging for 10 days in the first injected water $(\mathrm{PG})$ and one week in the second injected water (PG3\#S).

\section{Results and discussion}

The main goal of this study is to find an approach to make the conventional water flooding more efficient in 


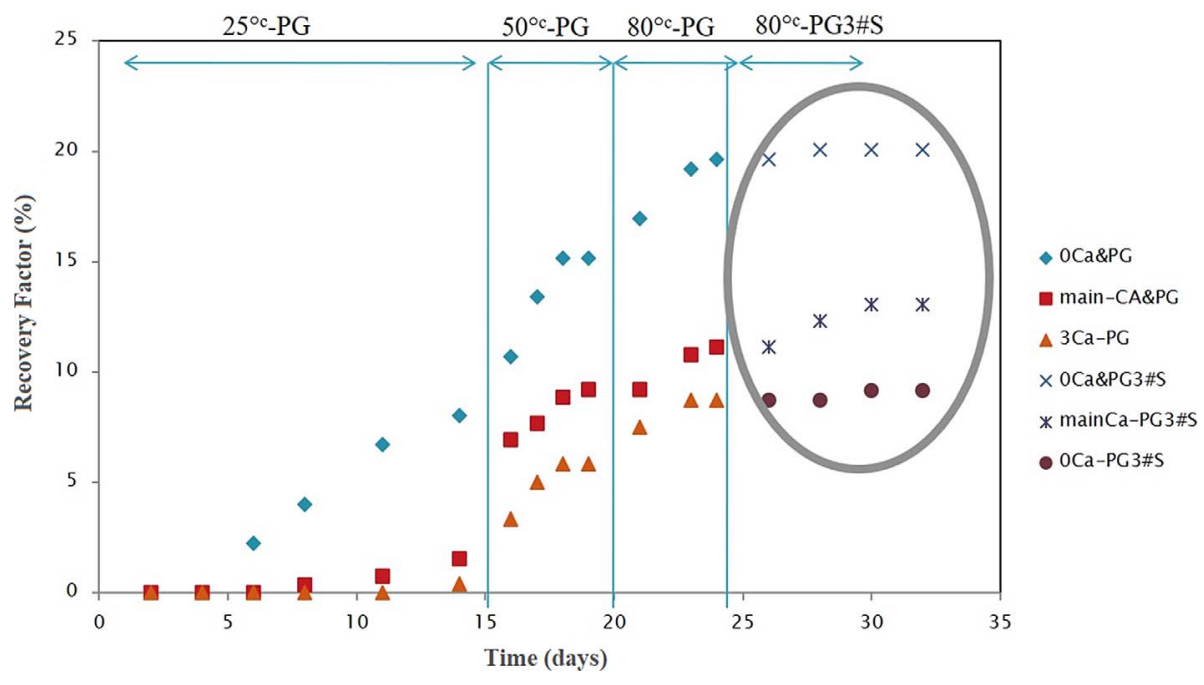

Fig. 2. The results of spontaneous imbibition experiments at different temperatures.

carbonated reservoirs. Several examinations were conducted to identify governing mechanisms entailed in oil extraction and the effect of salinity and different types of ionic contents contained in FW and injected fluid. The reason for putting them under assessment is their role in wettability alteration as a promising target to have more oil recovery in carbonated rocks.

As a result, for a better explanation of the governing mechanisms, the experimental tests were divided into three different stages of time. The first period is covering before injection (before and after the aging process in oil), the second period is after conducting of seawater injection, and the third one focused on the effect of smart water injection.

\subsection{First period: before and after aging in oil}

The aging process is the stage of imposing the initial water migration into the reservoir over geological time and oil infiltration to change wettability into oil-wet. Subsequent to this migration, a portion of formation water remains as the irreducible water saturation $\left(S_{w_{\text {ir }}}\right)$ that trapped in narrow pathways. Observations were made on sample slices correspondent to different formation water cases before and after the aging period adjacent to the oil for three weeks. It showed that in the case of 3-Ca FW, contact angles of slices extended from $36.19^{\circ}$ to $139.4^{\circ}$. The changes in the other two waters (Main-Ca and 0-Ca) were from $37.4^{\circ}$ to $131.4^{\circ}$ and $36.96^{\circ}$ to $92.42^{\circ}$ respectively. These experiences are depicted in Figure 3.

According to Figure 3, it is obvious that the sample with 3-Ca FW case becomes more oil-wet after aging process. This hypothesis can be verified due to high positive charge density (ionic strength) in the plugs in the vicinity of highcalcium FW since carboxylate components of oil attain much more absorption to carbonate rock surface because of the initial negative charge (Fig. 4). Also from the contact angle experiment and observed changes, the slices that are saturated by 3-Ca FW are remarkably more attendant to provide oil-wet condition than the other slices after aging.

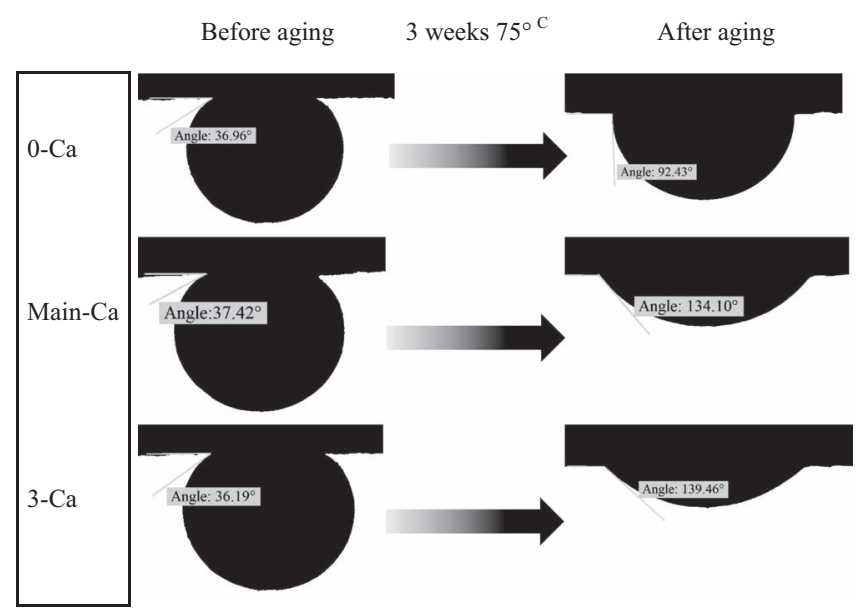

Fig. 3. Contact angle changes for various formation water before and after the aging.

The change of contact angle in zero calcium content FW cases was negligible and a value about $90^{\circ}$ reported for them, so the surface is characterized as an intermediatewet system. The behavior of the rock surface relative to the various positive charge densities can be schematically detected in Figure 4. As seen in this figure, when the concentration of calcium in the water is high, the positive charge density increases on the surface of the rock. As a result, the carboxylic acids in the oil are more bonded to the carbonate surface due to their negative charge. In other words, the surface of these rocks is remarkably more attendant to provide oil-wet condition. Similar explanation was discussed by Standnes and Austad [50].

Also, the amount of this wettability, quantified by contact angle, versus the oil extracted after flooding, assigned from relative permeability curves, can be compared qualitatively to offer more transparency of the examinations. Due to inevitable short duration of water fingering 


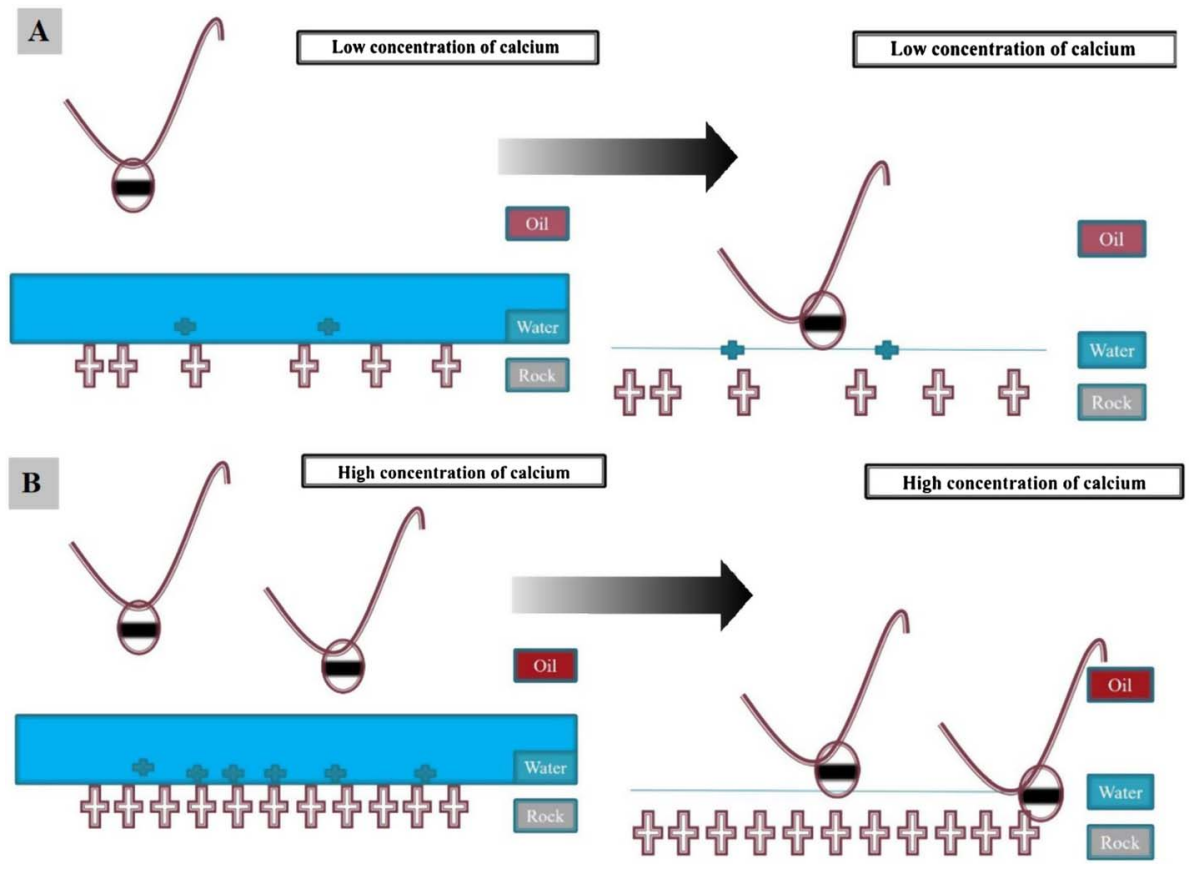

Fig. 4. Schematic of oil-wet of rock with formation water (A) low concentration of calcium and (B) high concentration of calcium.
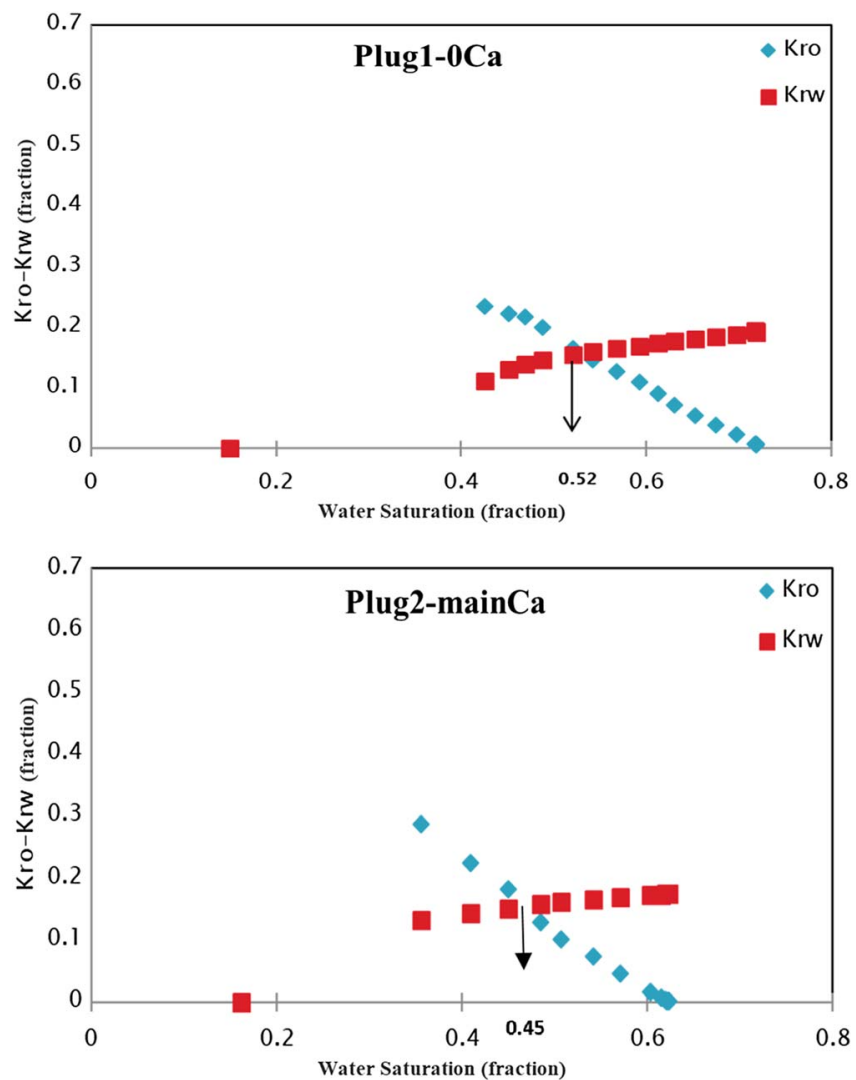

Fig. 5. The relative permeability curves Plug (1) formation water with zero concentration of calcium. Plug (2) formation water with the main concentration of calcium.

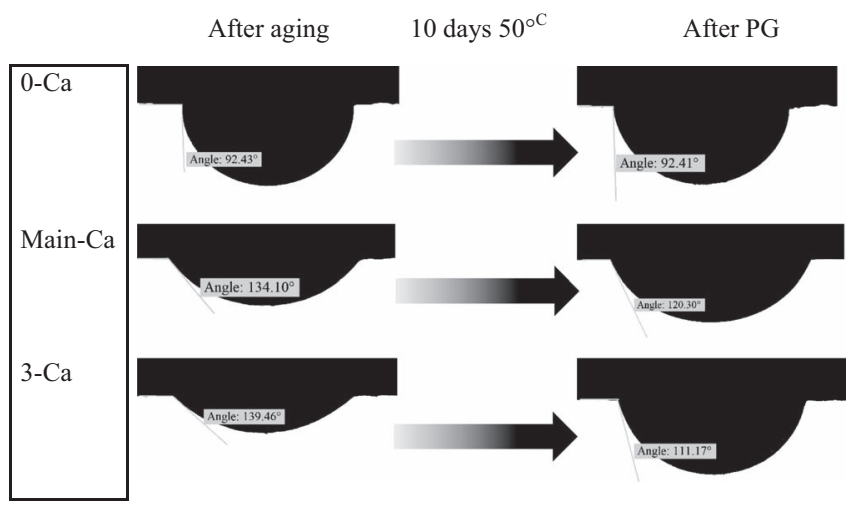

Fig. 6. Changes in contact angle after adjacent slices for 10 days in $\mathrm{PG}$ water at $50{ }^{\circ} \mathrm{C}$.

in high oil-wet cases, (in a concentration of three times of the calcium), it was not possible to draw relative permeability curves using JBN model but for two other cases, relative permeability was calculated (Fig. 5). As shown in Figure 5, the intersection point of relative permeability curve of oil and water in a plug with no calcium contents FW (0-Ca) has displayed more than 0.5 (approximately $52 \%$ ) of water saturation. However, for the plug with the main calcium concentration FW (Main-Ca), the intersection has occurred at water saturation of 0.45 pointing out that the plug with a high concentration of calcium tends to be oil-wet.

\subsection{Second period: seawater injection (PG)}

In the following, the oil-wet slices are exposed to the seawater for 10 days at $50{ }^{\circ} \mathrm{C}$ and the contact angle has dropped 


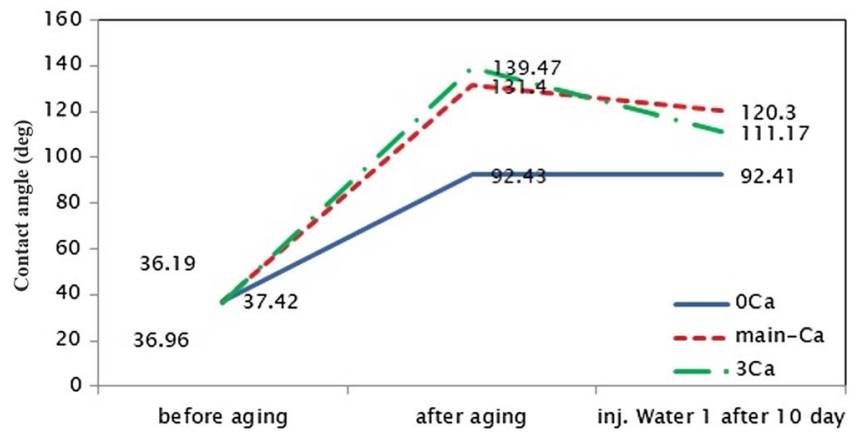

Fig. 7. Changes in contact angle in the vicinity of slides with seawater after 10 days.

as shown in Figure 6. In other words, the improvement in wettability to a higher degree of water-wetness (magnitude of wettability change) is more significant in high calcium concentration samples.

The 3-Ca FW cases, with the contact angle reduction of $28.3^{\circ}$ (from 139.47 to 111.17 ), Main-Ca with $13.8^{\circ}$ (from 134.1 to 120.3 ) and 0 -Ca with only $0.02^{\circ}$ (from 92.43 to 92.41 ) are showing the wettability change potential for each condition respectively. Regarding mechanisms aiding wettability improvement, despite the fact that the formation with high calcium content tends more to oil-wetness, this time the underlying parameter is calcium content, which has a significant effect in contact angle changes. In order to have a clear understanding of this parameter, Figure 7 presents a prediction of calcium content effect assuming the same initial wettability for slices. In the case of low calcium content on the rock surface, the positive charge density decreases that consequences lower amounts of sulfate. In addition, the continuation of wettability improvement process itself (even by taking into account the partial absorption of sulfate) would reduce the calcium ion content to form the complex and release the carboxylic group. On the contrary, as calcium portion increases, it facilitates separation of oilwetting materials and the environment will tend to be more water-wet. This mechanism is depicted in Figure 8 similar to the mechanism proposed by Standnes and Austad [50].

These results are compared with the oil recovery data reported by flooding tests. This analogical survey demonstrated that 0-Ca FW plug, with $67.2 \%$ (Fig. 9), 3 -Ca FW plug with $64.8 \%$ (Fig. 10), and Main-Ca with $55.2 \%$ (Fig. 11) of oil recovery which shows the highest to lowest ranks in the flood performance. The 0-Ca noticeable lead is due to its water-wet nature.

In spontaneous imbibition tests, 0-Ca FW plug shows the highest oil recovery due to its water intermediate wettability but 3-Ca plug shows less recovery in compare with the Main-Ca plug (Fig. 12). Values of recovery from this mechanism are as shown in Figure 13.

Recovery improvements were estimated $19.4 \%$ for $0-\mathrm{Ca}$ FW, $11.15 \%$ for Main-Ca, and $8.75 \%$ for 3 -Ca As it was expected 0-Ca shows the highest recovery due to its tendency to water-wet systems (Contact angle was lower in compare with other cases). Regarding to the nonconforming results of spontaneous imbibition tests for two other samples and considering obtained results from the contact angle and flood tests, two scenarios can be proposed to explain this behavior:

The first possible scenario is the precipitation of calcium sulfate. When there is a lack of calcium and sulfate ion concentrations, as happened in 0-Ca and Main-Ca cases in the vicinity of seawater, it is not probable to form Calcium-Sulfate at low temperature. Therefore, the mechanism in charge of natural wettability improvement is described according to the procedures discussed before

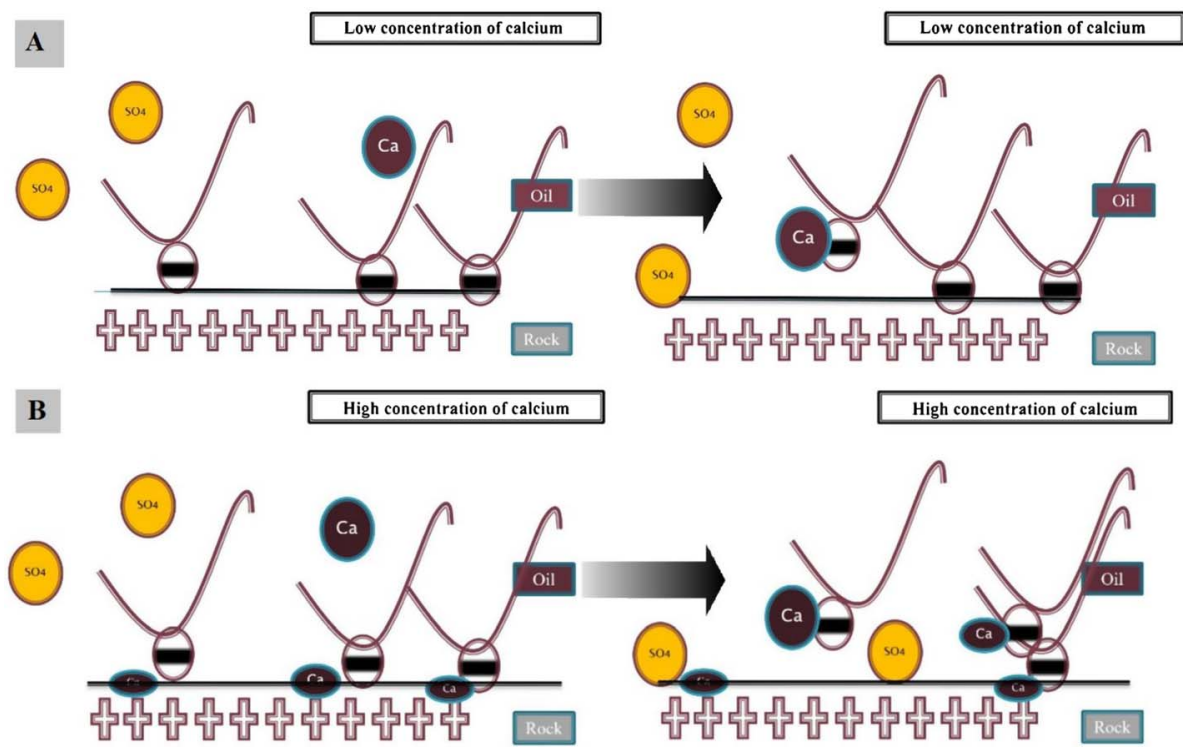

Fig. 8. A mechanism for comparing the effect of various concentrations of calcium in the formation water for separation (A) low concentration of calcium and (B) high concentration of calcium. 


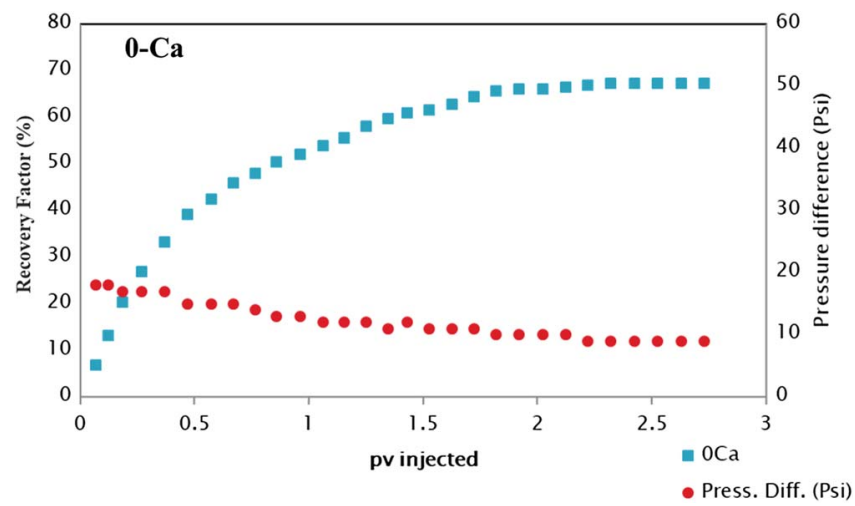

Fig. 9. Recovery and pressure drop for PG flooding in 0-Ca FW plug.

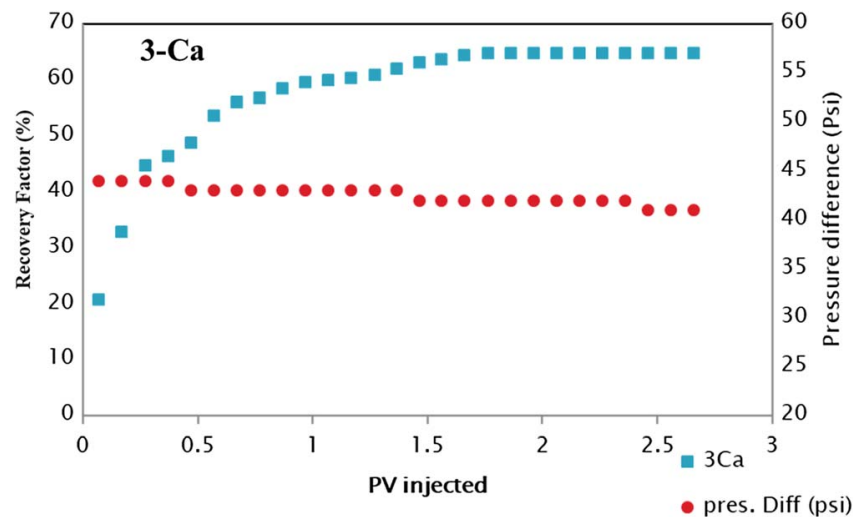

Fig. 10. Recovery and pressure drop for PG flooding in 3-CA FW plug.

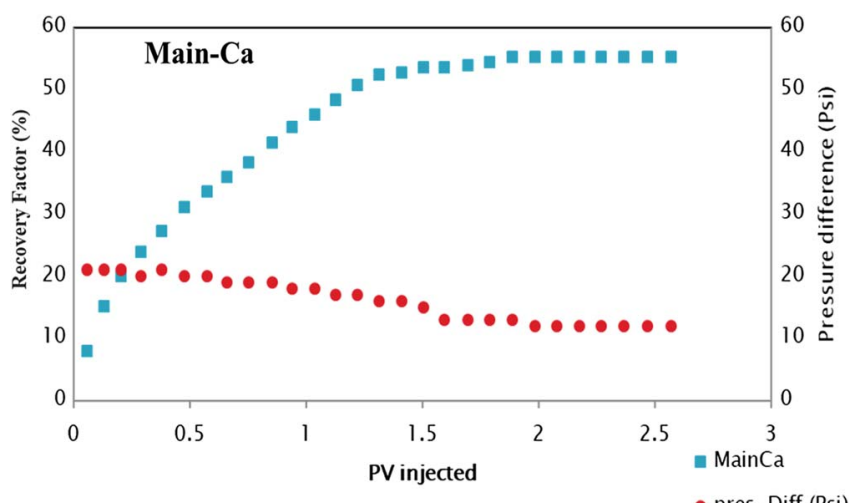

Fig. 11. Recovery and pressure drop for PG flooding in MainCa FW plug.

and the running process in porous space process can be shown as Figure 14.

Now in a 3-Ca water-flooded plug, the precipitation of calcium sulfate may occur at various concentration but increases by rising the temperature. In the existence of



Fig. 12. Amott wettability cell (spontaneous imbibition) for three kinds of formation brines.

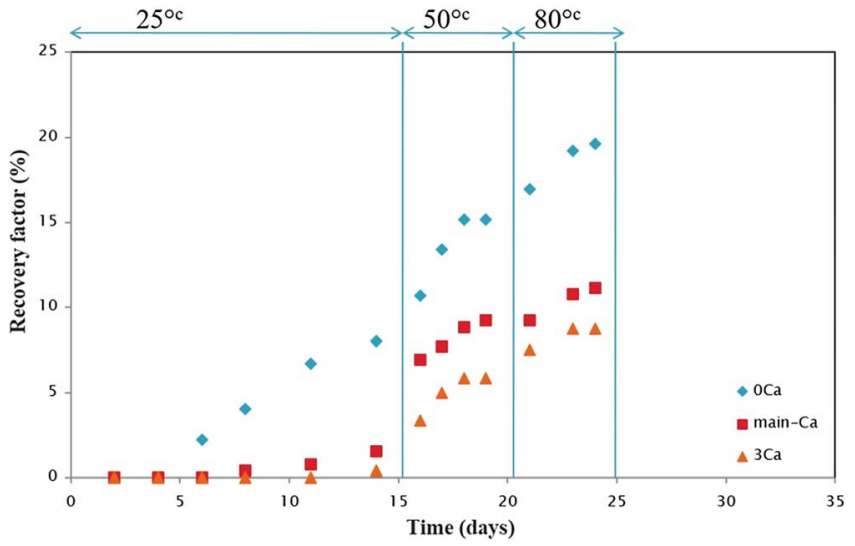

Fig. 13. Spontaneous imbibition results for different formation water in the vicinity of $\mathrm{PG}$ at 25,50 , and $80{ }^{\circ} \mathrm{C}$.

sulfate and its absorption on the rock surface, in addition to changing the wettability and release the carboxylic group from the interface, there is also a potential for the deposition. This fact is imaged by additional pressure gradient recorded in data to show the possibility of the phenomenon (Fig. 10). Following the precipitation of calcium sulfate, rationally pore spaces will tend to contract or even block. This effect intensifies considering in high-permeability pathways with tight throats to take the majority of current flow. Since that additional pressure drop, it can result in formation to build up new openings. In overall, the precipitation of calcium-sulfate causes higher pressure drop and more viscous force and lead to increase in sweep efficiency and having more oil recovery (Fig. 15).

Sulfate encroachment and deposition on the formation is depicted in sub-plot (1) and (2), which provide wettability alteration. Subsequently, it is clearly mentioned on subplot (3) that in the presence of high calcium content, a very fortunate possibility is created to initiate calcium-sulfate depositions causing more sulfate extent (sub-plots (4) and (5)). This criteria will make more pressure gradient to push stuck carboxylic groups off the walls (sub-plot (6)) and new 
1
504
504
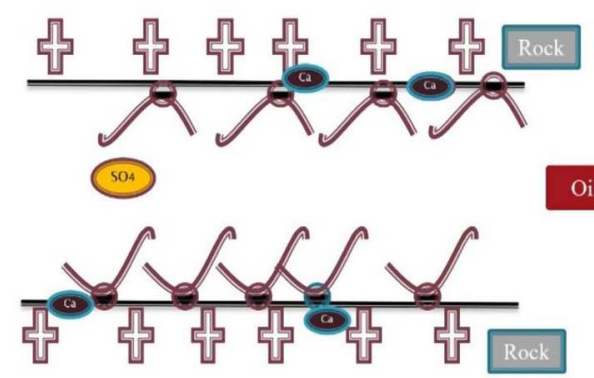

3
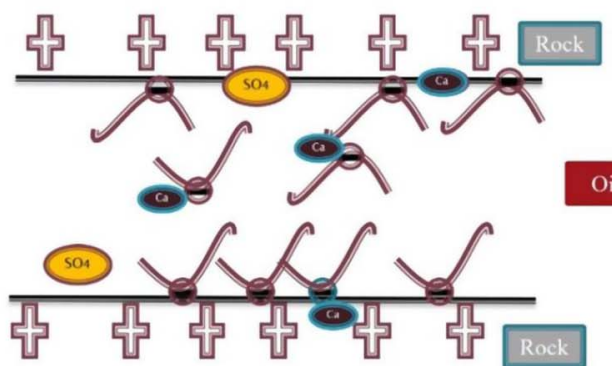

2

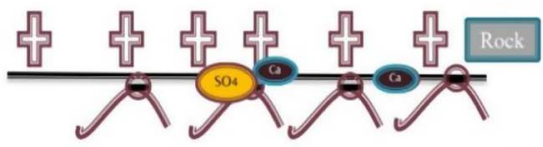

Oil

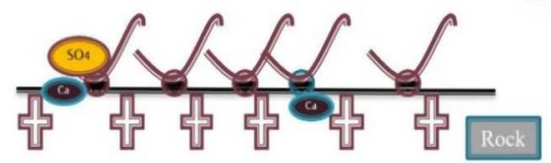

4

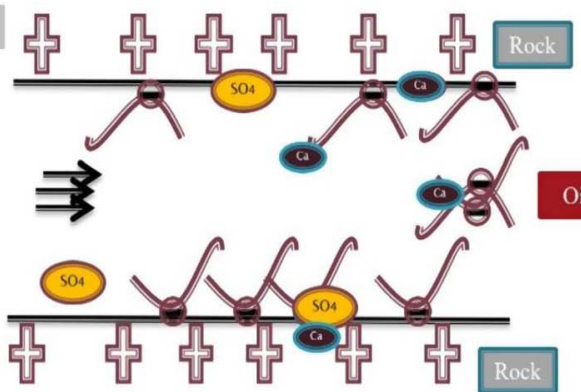

Fig. 14. The mechanism of cross-sectional wettability alteration in Main-Ca FW with PG injection.
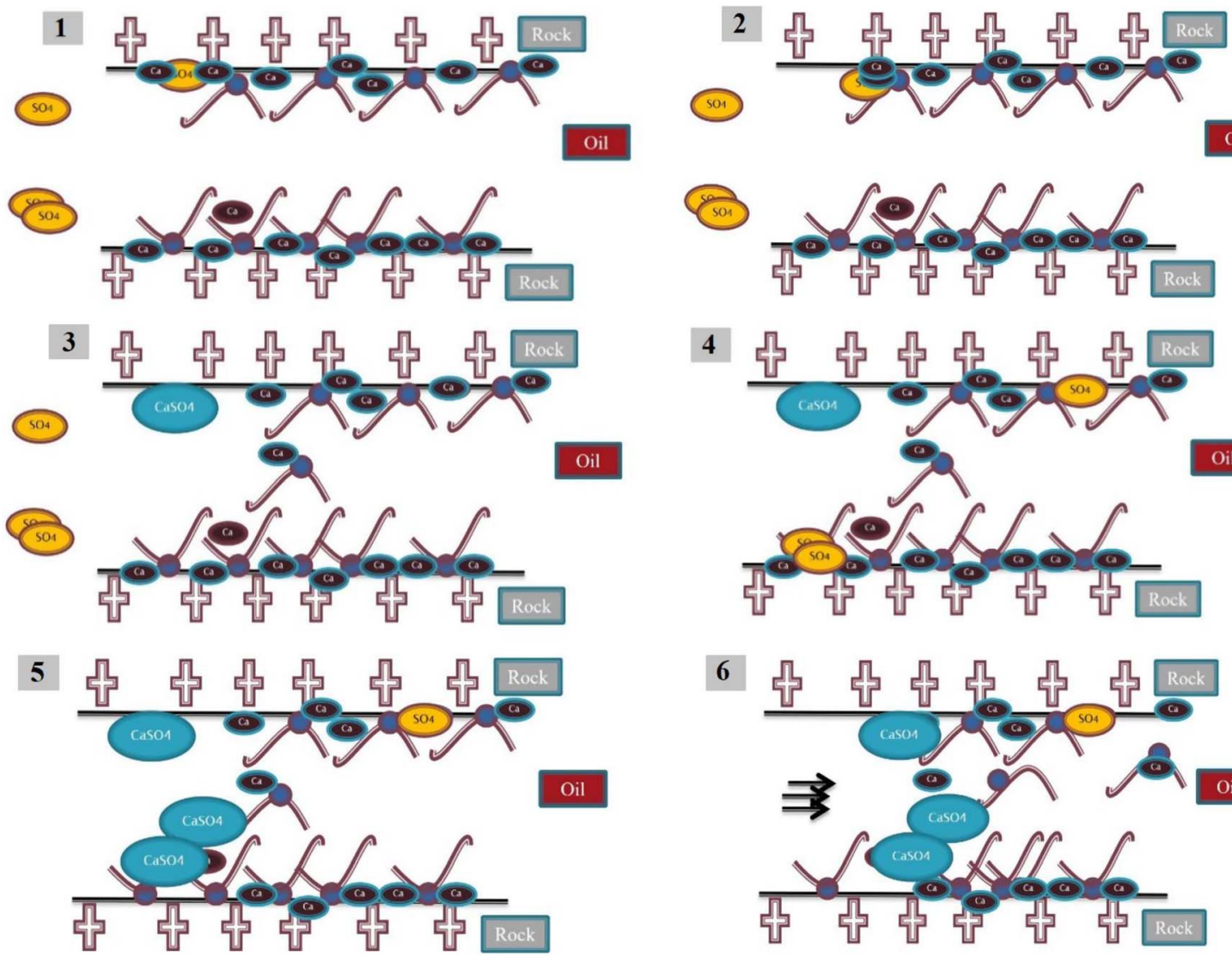

Oil

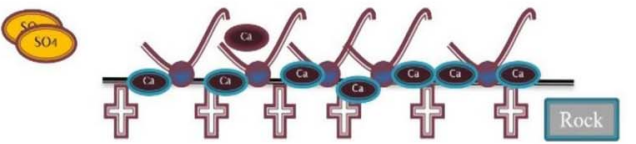

4

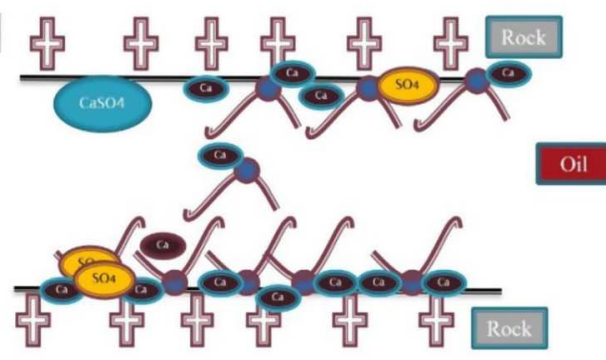

6

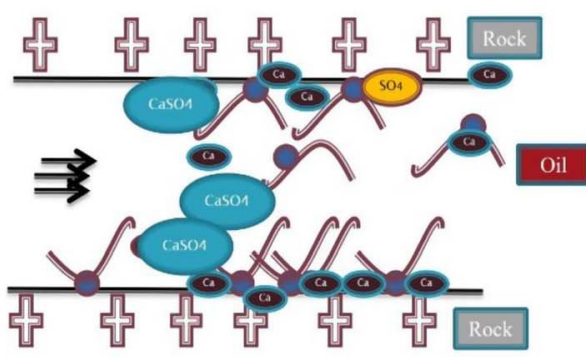

Fig. 15. Porous media and the mechanism of the precipitation of calcium sulfate in the 3-Ca FW by PG or PG3\#S injection.

flowing passages lead to improve the sweep efficiency. Since in the sponteneous imbibition test, the issue of oil recovery by forced displacement with injected water is not discussed, these pressure gradiens are not observed. As a result, the precipitation of calcium sulfate can reduce oil recovery through pore throat blockage. 
$\mathbf{A}$

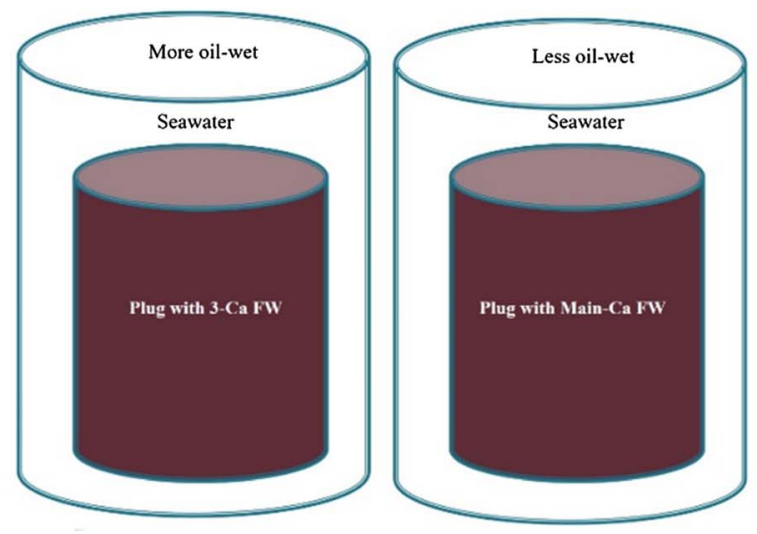

B

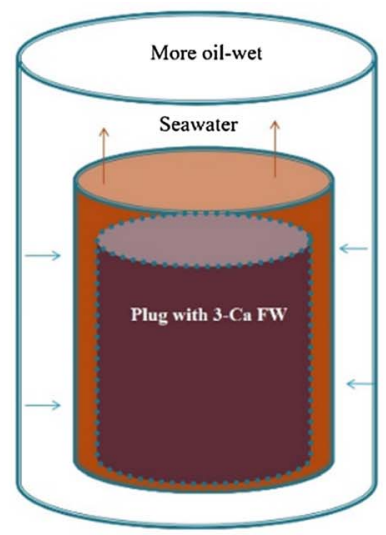

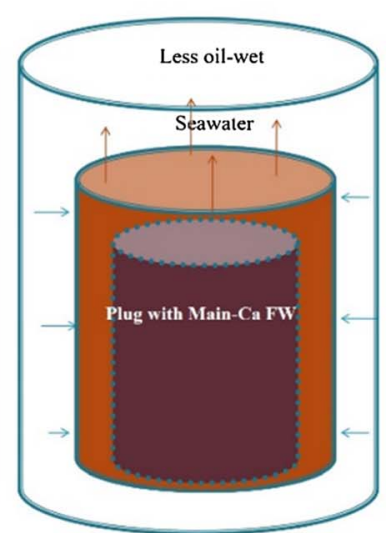

Fig. 16. Plug-ins (A) before being adjacent to the water in the imbibition cell and (B) after placement.

The second possible mechanism is considered without taking precipitation of calcium sulfate is presented in Figure 16. In these cases, due to the fact that in flooding, there is a full contact between the pore space and injected seawater, we can expect that wettability alteration can happen completely and situation can be more similar to the contact angle measurement. While in imbibition tests, only outer faces of the cores are in contact with water, therefore wettability alteration only can happen in outer contact area and main body will be untouched. In other word there is lower wettability alteration for 3-Ca case it most body will preserve its high oil-wet tendency. Therefore in imbibition tests, recovery of $3-\mathrm{Ca}$ is the lowest but in flooding test, recovery of Main-Ca is the lowest.

\subsection{Third period: second water injection (Smart Water PG3\#S)}

After slices were put for one week in the smart water $(\mathrm{PG} 3 \# \mathrm{~S})$ at $50{ }^{\circ} \mathrm{C}$ to observe the wettability alteration of new injected water, the change or improvement of contact angle for the plug with 3-Ca FW was recorded to decline from 111.17 to 92.34, for Main-Ca from 120 to 109.94, and for 0 -Ca from 92.41 to 91.74 . Figure 17 delineates that sulfate ions increase plays a vital role in improving the wettability of calcium-containing water.

The angle variations during different periods (Fig. 18) and the reason of the shifting of contact angle toward water-wet system is the presence of sufficient sulfate ions. Sulfate ions can remove more sticking carboxylic from the surface. According to the oil extraction data of imbibition experiments on the cores were placed for eight days in the vicinity of the second injected water, it was acquired that for the plugs with Main-Ca, 3-Ca, and 0-Ca FW there is an increase in oil recovery in order of $1.92 \%, 0.44 \%$, and $0.41 \%$ respectively.

In the following, by comparing the recovery curves obtained from flooding tests (Fig. 19), a relatively significant increase is represented in PG3\#S injected water into the Main-Ca FW filling plug. Low incremental oil recovery for 3-Ca case can be the possibility that most of the remaining oil was swept in the Previous Flooding (PG) where higher pressure drop can support the hypothesis of



Fig. 17. Contact angle changes in slices after one week in $3 \mathrm{PG} \# \mathrm{~S}$ water at $50{ }^{\circ} \mathrm{C}$.

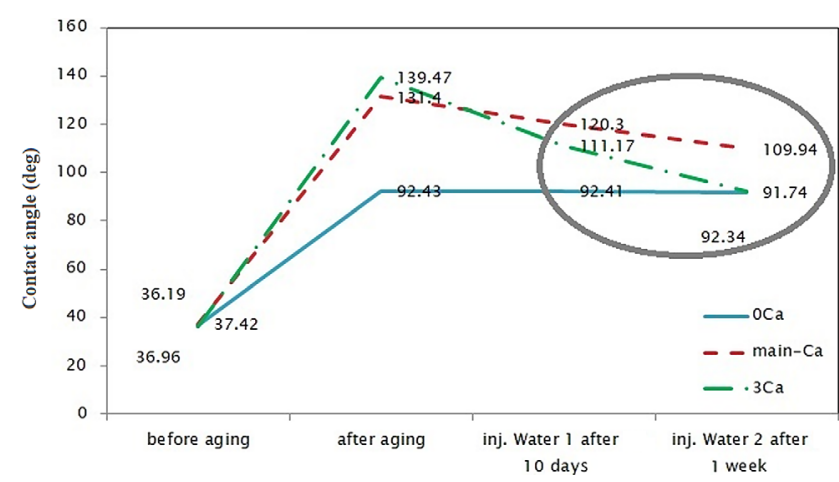

Fig. 18. Contact angles of different formation waters during different periods.

sulfate precipitation and imposing more viscous forces. In all three main tests (contact angle, imbibition, and flooding after second water flooding) 0 -Ca sample shows more water-wet tendency and consequently has the highest oil recovery.

In summary, the results of flooding, imbibition, and contact angle tests are presented in Tables 5-7 to offer a more comprehensive insight into the whole process. 


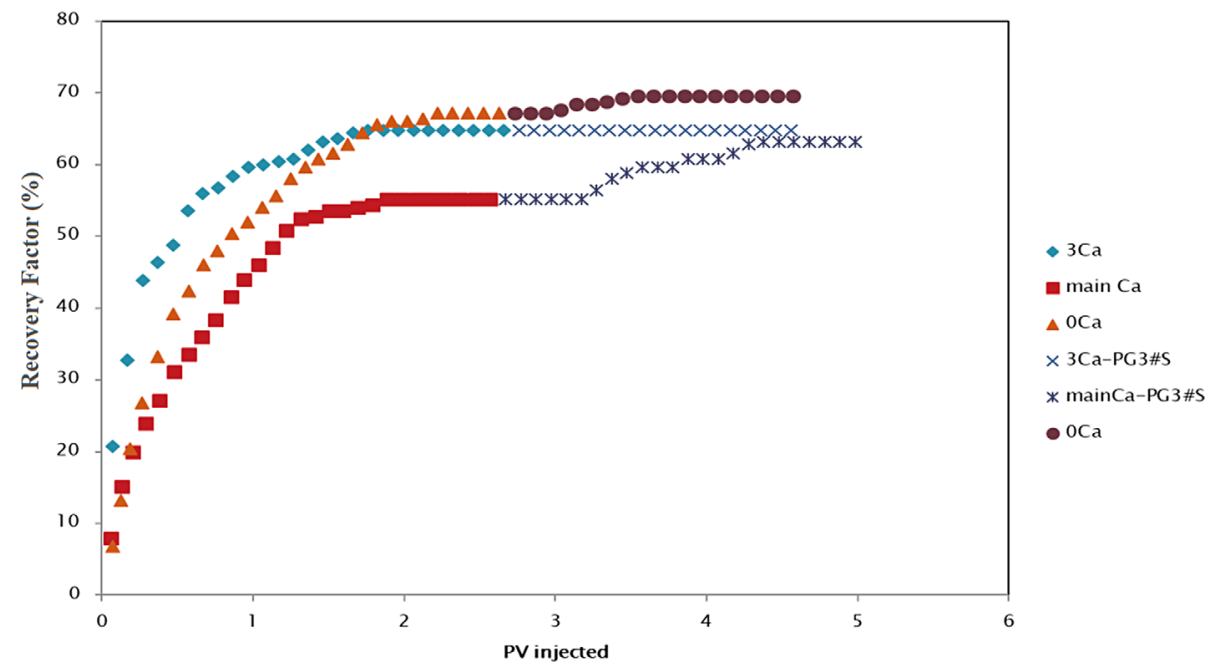

Fig. 19. Recovery curves from flood testing.

Table 5. Results obtained from water flooding tests.

\begin{tabular}{lccccccc}
\hline Information & $\begin{array}{c}\text { Brine porosity } \\
(\%)\end{array}$ & $\begin{array}{c}\text { Brine perm. } \\
(\mathrm{md})\end{array}$ & $S_{\mathrm{wi}}(\%)$ & $V_{p}(\mathrm{cc})$ & $\begin{array}{c}\text { PG rec. } \\
(\%)\end{array}$ & $\begin{array}{c}\text { PG3\#S } \\
\text { rec. }(\%)\end{array}$ & $\begin{array}{c}\text { Final oil } \\
\text { rec. }(\%)\end{array}$ \\
\hline Plug 1 (0-Ca) & 16.7 & 21.01 & 14.5 & 14.62 & 67.2 & 69.6 & 25.1 \\
Plug 2 (main-Ca) & 17.1 & 25.06 & 16.2 & 14.92 & 55.2 & 63.2 & 30.8 \\
Plug 3 (3-Ca) & 17.2 & 19.9 & 16.7 & 15.02 & 64.8 & 64.8 & 29.3 \\
\hline
\end{tabular}

Table 6. Results obtained from imbibition tests.

\begin{tabular}{lccccccc}
\hline Information & $\begin{array}{c}\text { Brine porosity } \\
(\%)\end{array}$ & $\begin{array}{c}\text { Brine perm. } \\
(\mathrm{md})\end{array}$ & $S_{\mathrm{wi}}(\%)$ & $V_{p}(\mathrm{cc})$ & $\begin{array}{c}\text { PG rec. } \\
(\%)\end{array}$ & $\begin{array}{c}\text { PG3\#S } \\
\text { rec. }(\%)\end{array}$ & $\begin{array}{c}\text { Final oil } \\
\text { rec. }(\%)\end{array}$ \\
\hline Plug 34 (0-Ca) & 17.1 & 19.1 & 23.1 & 14.72 & 19.64 & 20.08 & 61.61 \\
Plug 36 (main-Ca) & 20.2 & 21.3 & 26.1 & 17.59 & 11.1 & 13.07 & 64.23 \\
Plug 31 (3-Ca) & 19.16 & 20.2 & 25.1 & 16.7 & 8.75 & 9.166 & 68.31 \\
\hline
\end{tabular}

Table 7. Results obtained from contact angle tests.

\begin{tabular}{lccccc}
\hline Angle & Before aging & After aging & PG & PG3\#S & \multicolumn{2}{c}{ Angle variation } \\
\hline 0-Ca & 36.96 & 92.43 & 92.41 & 91.74 & 0.67 \\
Main-Ca & 37.42 & 131.4 & 120.3 & 109.94 & 10.36 \\
3-Ca & 36.19 & 139.47 & 111.17 & 92.34 & 18.83 \\
\hline
\end{tabular}

\section{Conclusion}

In this paper, effective mechanisms of low salinity flooding on oil recovery of carbonated rocks were investigated. A sensitivity analysis was carried out to examine the effect of calcium ion concentration in the formation water composition on the oil recovery. Sulfate ion exchange in seawater is another parameter that was studied in this investigation. Several experiments including core-flooding and imbibition tests were conducted. In addition to that, several contact angle measurements were performed for calculating the water, oil, and rock interaction beside those tests. In the following, the summary of experiments and obtained results of the study is summarized: 
- Calcium ion in formation water is a very important factor in wettability degree based on experimental observation. It was observed that in the aging period of oil plugs, the sample with higher calcium content in formation water becomes more oil-wet.

- Since the formation water was used with different values of calcium content, it can be stated that the lower the calcium content in formation water, the initial contact angle was lower and it was not be changed significantly when slices were put beside different injected water. Based on experimental results performed in this work, existence of the high calcium concentration in the formation water (high ionic strength) would cause a significant change in initial wettability status of the rock and wettability change during low salinity water injection. It has been observed that presence of sulfate ion in injected brine (PG) would affect the ultimate oil recovery.

- In static experiments like contact angle tests, a gradual change is observed in wettability by increasing calcium concentration in formation water affirmed. Final recovery by flooding test also confirms the fact that more water-wet system (based on contact angle tests), will show higher oil recovery. In imbibition test although the 0-Ca case shows the highest oil recovery due to its original intermediate wettability status, but in the imbibition test, the recorded recovery for Main$\mathrm{Ca}$ and 3-Ca does not follow the contact angle measurement. This can be due to low contact between injected water and pores in the imbibition test in compare with flooding test.

\section{References}

1 Ahmed T. (2010) Reservoir Engineering Handbook. Gulf Professional Publishing, 4th edn., Elsevier, Burlington, USA, $1341 \mathrm{p}$.

2 Buckley J.S., Liu Y., Monsterleet S. (1998) Mechanisms of wetting alteration by crude oils, SPE J. 3, 1, 54-61.

3 Jadhunandan P.P., Morrow N.R. (1995) Effect of wettability on waterflood recovery for crude-oil/brine/rock systems, SPE Reserv. Eng., 10, 1, 40-46.

4 Xu J., Xu J., Wu K., Li Z., Li R., Chen Z. (2018) An improved analytical model for low-salinity waterflooding, J. Geophys. Eng. 15, 4, 1602-1609.

5 Yildiz H.O., Morrow N.R. (1996) Effect of brine composition on recovery of Moutray crude oil by waterflooding, J. Pet. Sci. Eng. 14, 3, 159-168.

6 Morrow N., Buckley J. (2011) Improved oil recovery by lowsalinity waterflooding, J. Pet. Technol. 63, 5, 106-112.

7 Zhang Y., Morrow N.R. (2006) Comparison of secondary and tertiary recovery with change in injection brine composition for crude-oil/sandstone combinations, in: SPE/DOE Symposium on Improved Oil Recovery, Society of Petroleum Engineers, Tulsa, OK, USA, $14 \mathrm{p}$.

8 Zhang P., Tweheyo M.T., Austad T. (2007) Wettability alteration and improved oil recovery by spontaneous imbibition of seawater into chalk: Impact of the potential determining ions $\mathrm{Ca}^{2+}, \mathrm{Mg}^{2+}$, and $\mathrm{SO}_{4}^{2-}$, Colloids Surf. A Physicochem. Eng. Aspects 301, 1, 199-208.
9 Fjelde I., Asen S.M., Omekeh A.V. (2012) Low salinity water flooding experiments and interpretation by simulations, in: SPE Improved Oil Recovery Symposium, Society of Petroleum Engineers, Tulsa, OK, USA, 12 p.

10 Hao J., Mohammadkhani S., Shahverdi H., Esfahany M.N., Shapiro A. (2019) Mechanisms of smart waterflooding in carbonate oil reservoirs - a review, J. Pet. Sci. Eng. 179, 276-291.

11 Sigmund P.M., McCaffery F.G. (1979) An improved unsteadystate procedure for determining the relative-permeability characteristics of heterogeneous porous media (includes associated papers 8028 and 8777), Soc. Pet. Eng. J. 19, 1, 15-28.

12 Strand S., Puntervold T., Austad T. (2008) Effect of temperature on enhanced oil recovery from mixed-wet chalk cores by spontaneous imbibition and forced displacement using seawater, Energy Fuels 22, 5, 3222-3225.

13 Webb K.J., Black C.J.J., Edmonds I.J. (2005) Low salinity oil recovery - the role of reservoir condition corefloods, in: 13th European Symposium on Improved Oil Recovery, European Association of Geoscientists \& Engineers, Budapest.

14 Mohammadkhani S., Shahverdi H., Esfahany M.N. (2018) Impact of salinity and connate water on low salinity water injection in secondary and tertiary stages for enhanced oil recovery in carbonate oil reservoirs, J. Geophys. Eng. 15, 4, 1242-1254.

15 AlHammadi M., Mahzari P., Sohrabi M. (2018) Fundamental investigation of underlying mechanisms behind improved oil recovery by low salinity water injection in carbonate rocks, Fuel 220, 345-357.

16 RezaeiDoust A., Puntervold T., Strand S., Austad T. (2009) Smart water as wettability modifier in carbonate and sandstone: A discussion of similarities/differences in the chemical mechanisms, Energy Fuels 23, 9, 4479-4485.

17 Skrettingland K., Holt T., Tweheyo M.T., Skjevrak I. (2011) Snorre low-salinity-water injection-coreflooding experiments and single-well field pilot, SPE Reserv. Evalu. Eng. 14, 2, 182-192.

18 Sharma M.M., Filoco P.R. (2000) Effect of brine salinity and crude-oil properties on oil recovery and residual saturations, SPE J. 5, 3, 293-300.

19 McGuire P.L., Chatham J.R., Paskvan F.K., Sommer D.M., Carini F.H. (2005) Low salinity oil recovery: An exciting new EOR opportunity for Alaska's North Slope, in: SPE Western Regional Meeting, Society of Petroleum Engineers, Irvine, CA, 15 p.

20 Fathi S.J., Austad T., Strand S., Puntervold T. (2010) Wettability alteration in carbonates: The effect of water-soluble carboxylic acids in crude oil, Energy Fuels 24, 5, 2974-2979.

21 Seccombe J., Lager A., Jerauld G., Jhaveri B., Buikema T., Bassler S., Denis J., Webb K., Cockin A., Fueg E. (2010) Demonstration of low-salinity EOR at interwell scale, Endicott field, Alaska, in: SPE Improved Oil Recovery Symposium, Society of Petroleum Engineers, Tulsa, OK, USA, 12 p.

22 Nasralla R.A., Mahani H., van der Linde H.A., Marcelis F. H., Masalmeh S.K., Sergienko E., Brussee N.J., Pieterse S.G., Basu S. (2018) Low salinity waterflooding for a carbonate reservoir: Experimental evaluation and numerical interpretation, J. Pet. Sci. Eng. 164, 640-654.

23 Chandrasekhar S., Sharma H., Mohanty K.K. (2016) Wettability alteration with brine composition in high temperature carbonate rocks, in: SPE Annual Technical Conference and Exhibition, Society of Petroleum Engineers, Dubai, UAE, 21 p. 
24 Sharifi M., Shaikh M. (2013) Investigation of optimum salinity of injected water in carbonate reservoirs using wettability measurement and core flooding, in: SPE Reservoir Characterization and Simulation Conference and Exhibition, Society of Petroleum Engineers, Abu Dhabi, UAE, 11 p.

25 Standnes D.C., Austad T. (2003) Wettability alteration in carbonates: Interaction between cationic surfactant and carboxylates as a key factor in wettability alteration from oil-wet to water-wet conditions, Colloids Surf. A Physicochem. Eng. Aspects 216, 1, 243-259.

26 Austad T., Strand S., Høgnesen E.J., Zhang P. (2005) Seawater as IOR fluid in fractured chalk, in: SPE International Symposium on Oilfield Chemistry, Society of Petroleum Engineers, The Woodlands, TX, 10 p.

27 Zhang P., Austad T. (2006) Wettability and oil recovery from carbonates: Effects of temperature and potential determining ions, Colloids Surf. A Physicochem. Eng. Aspects 279, 1, 179-187.

28 Mahani H., Keya A.L., Berg S., Bartels W.B., Nasralla R., Rossen W. (2015) Driving mechanism of low salinity flooding in carbonate rocks, in: EUROPEC 2015, Society of Petroleum Engineers, Madrid, Spain, 27 p.

29 Blin N., Ruiz J., Pardo R. (2018) A laboratory approach to evaluate the efficiency of low salinity brine injection for enhancing oil recovery at high temperature in carbonate reservoirs, in: RDPETRO 2018: Research and Development Petroleum Conference and Exhibition, 9-10 May 2018, Abu Dhabi, UAE, American Association of Petroleum Geologists, Society of Exploration Geophysicists, European Association of Geoscientists and Engineers, and Society of Petroleum Engineers, pp. $12-15$.

30 Nasralla R.A., Sergienko E., Masalmeh S.K., van der Linde H.A., Brussee N.J., Mahani H., Suijkerbuijk B.M., AlQarshubi I.S. (2016) Potential of low-salinity waterflood to improve oil recovery in carbonates: Demonstrating the effect by qualitative coreflood, SPE J. 21, 5, 1643-1654.

31 Qiao C., Li L., Johns R.T., Xu J. (2014) A mechanistic model for wettability alteration by chemically tuned water flooding in carbonate reservoirs, in: SPE Annual Technical Conference and Exhibition, Society of Petroleum Engineers, Amsterdam, The Netherlands, 29 p.

32 Gupta R., Smith G.G., Hu L., Willingham T., Lo Cascio M., Shyeh J.J., Harris C.R. (2011) Enhanced waterflood for carbonate reservoirs - impact of injection water composition, in: SPE Middle East Oil and Gas Show and Conference, Society of Petroleum Engineers, Manama, Bahrain, 21 p.

33 Ligthelm D.J., Gronsveld J., Hofman J., Brussee N., Marcelis F., Linde H. (2009) Novel waterflooding strategy by manipulation of injection brine composition, in: EUROPEC/EAGE Conference and Exhibition, Society of Petroleum Engineers, Amsterdam, The Netherlands, 22 p.

34 Seyyedi M., Tagliaferri S., Abatzis J., Nielsen S.M. (2018) An integrated experimental approach to quantify the oil recovery potential of seawater and low-salinity seawater injection in North Sea chalk oil reservoirs, Fuel 232, $267-278$.

35 Fathi S.J., Austad T., Strand S. (2010) "Smart Water" as a wettability modifier in chalk: The effect of salinity and ionic composition, Energy Fuels 24, 4, 2514-2519.
36 Strand S., Høgnesen E.J., Austad T. (2006) Wettability alteration of carbonates - effects of potential determining ions $\left(\mathrm{Ca}^{2+}\right.$ and $\left.\mathrm{SO}_{4}^{2-}\right)$ and temperature, Colloids Surf. A Physicochem. Eng. Aspects 275, 1, 1-10.

37 Yousef A.A., Al-Saleh S., Al-Kaabi A.U., Al-Jawfi M.S. (2010) Laboratory investigation of novel oil recovery method for carbonate reservoirs, in: Canadian Unconventional Resources and International Petroleum Conference, Society of Petroleum Engineers, Calgary, AB, Canada, 35 p.

38 Yousef A.A., Al-Salehsalah S.H., Al-Jawfi M.S. (2011) New recovery method for carbonate reservoirs through tuning the injection water salinity: Smart waterflooding, in: $S P E$ EUROPEC/EAGE Annual Conference and Exhibition, Society of Petroleum Engineers, Vienna, Austria, 16 p.

39 Yousef A.A., Al-Saleh S., Al-Jawfi M.S. (2012) Improved/ enhanced oil recovery from carbonate reservoirs by tuning injection water salinity and ionic content, in: SPE Improved Oil Recovery Symposium, Society of Petroleum Engineers, Tulsa, OK, USA, 18 p.

40 Yousef A.A., Al-Saleh S., Al-Jawfi M.S. (2012) The impact of the injection water chemistry on oil recovery from carbonate reservoirs, in: SPE EOR Conference at Oil and Gas West Asia, Society of Petroleum Engineers, Muscat, Oman, 14 p.

41 Al-Shalabi E.W., Sepehrnoori K., Delshad M. (2012) Mechanisms behind low salinity water flooding in carbonate reservoirs, in: SPE Western Regional \& $A A P G$ Pacific Section Meeting 2013 Joint Technical Conference, Society of Petroleum Engineers, Monterey, California, USA, 18 p.

42 Al-Shalabi E.W., Sepehrnoori K., Pope G. (2015) New mobility ratio definition for estimating volumetric sweep efficiency of low salinity water injection, Fuel 158, 664-671.

43 Al-Shalabi E.W., Sepehrnoori K., Delshad M. (2014) Mechanisms behind low salinity water injection in carbonate reservoirs, Fuel 121, 11-19.

44 Kozaki C. (2012) Efficiency of low salinity polymer flooding in sandstone cores, Doctoral dissertation, Petroleum and Geosystems Engineering, The University of Texas at Austin..

45 Kazemi Nia Korrani A., Jerauld G.R., Sepehrnoori K. (2016) Mechanistic modeling of low-salinity waterflooding through coupling a geochemical package with a compositional reservoir simulator, SPE Reserv. Evalu. Eng. 19, 1, 142-162.

46 Kazemi Nia Korrani A., Sepehrnoori K., Delshad M. (2013) A novel mechanistic approach for modeling low salinity water injection, in: SPE Annual Technical Conference and Exhibition, Society of Petroleum Engineers, New Orleans, LA, USA, $18 \mathrm{p}$.

47 Qiao C., Johns R., Li L. (2016) Modeling low-salinity waterflooding in chalk and limestone reservoirs, Energy Fuels 302, 884-895.

48 Qiao C., Johns R., Li L., Xu J. (2015) Modeling low salinity waterflooding in mineralogically different carbonates, in: SPE Annual Technical Conference and Exhibition, Society of Petroleum Engineers, Houston, TX, USA, 20 p.

49 Purswani P., Karpyn Z.T. (2019) Laboratory investigation of chemical mechanisms driving oil recovery from oil-wet carbonate rocks, Fuel 235, 406-415.

50 Standnes D.C., Austad T. (2000) Wettability alteration in chalk: 1. Preparation of core material and oil properties, $J$. Pet. Sci. Eng. 28, 3, 111-121. 